\title{
ANALISIS KNOWLEDGE CREATION DALAM INSTITUSI PENDIDIKAN DAN PELATIHAN
}

\author{
Denny Gunawan ${ }^{1}$, Teguh Kurniawan ${ }^{2}$ \\ Universitas Indonesia ${ }^{1,2}$ \\ dennygunawan8@gmail.com ${ }^{1}$
}

\begin{abstract}
ABSTRAK
Penelitian ini bertujuan untuk menganalisis proses knowledge creation dan kendala yang dihadapi di Pusat Pendidikan dan Pelatihan pegawai Kementerian Ketenagakerjaan ditinjau dari pendekatan SECI Nonaka. Penelitian dilakukan dengan metode Kualitatif, dengan menggunakan analisis studi literatur pada jurnal, buku, maupun berita tentang analisis knowledge creation terutama terkait institusi Pendidikan dan Pelatihan. Hasil analisis mendapatkan tiga model pendekatan yang dapat digunakan sebagai rujukan dalam menganalisa proses knowledge creation. Model pertama yaitu model knowledge creation Soo, model kedua adalah model Boisot, dan model ketiga adalah model SECI Nonaka yang menekankan pada penciptaan pengetahuan baru di organisasi melalui konversi pengetahuan tacit dan explicit dengan dimensi Socialization, Externalization, Combination dan Internalization. Simpulan, pendidikan dan pelatihan memerlukan model pembelajaran yang sesuai untutk menentukan calon peserta yang perlu untuk mengikuti pelatihan, materi dan keahlian apa saja yang dibutuhkan, menentukan pengajar yang akan memberikan materi pelatihan, pengelolaan mekanisme pembelajaran dalam kelas, dan rencana pembelajaran. Oleh karena itu penulis menyajikan tiga model pendekatan yang dapat digunakan sebagai rujukan dalam menganalisa proses knowledge creation.
\end{abstract}

Kata Kunci: Penciptaan Pengetahuan, Pendidikan dan Pelatihan, Tenaga Kerja

\begin{abstract}
This study aims to analyze the knowledge creation process and the obstacles faced by the Ministry of Manpower's Employee Training and Education Center in terms of the SECI Nonaka approach. The research was conducted using a qualitative method, using analysis of literature studies on journals, books, and news about knowledge creation analysis, especially related to education and training institutions. The results of the analysis obtained three model approaches that can be used as a reference in analyzing the knowledge creation process. The first model is Soo's knowledge creation model, the second model is the Boisot model, and the third model is the SECI Nonaka model which emphasizes the creation of new knowledge in the organization through the conversion of tacit and explicit knowledge with the dimensions of Socialization, Externalization, Combination and Internalization. In conclusion, education and training require an appropriate learning model to determine potential participants who need to take part in the training, what materials and skills are needed, determine which instructors will provide training material, manage in-class learning mechanisms, and lesson
\end{abstract}


plans. Therefore, the authors present three model approaches that can be used as a reference in analyzing the knowledge creation process.

Keywords: Knowledge Creation, Education and Training, Labor

\section{PENDAHULUAN}

Tantangan besar di dunia dalam menghadapi kiris ekonomi global pada saat ini adalah kemiskinan dan penggangguran. Hal tersebut terlihat dalam ringkasan Executive Summary World Employment and Social Outlook Trends 2020 yang di terbitkan oleh International Labour Organization (ILO). Menurut (Van Gent et al., 2019) dalam penelitiannya mengenai Efek Industri pada Pengangguran Pria dan Wanita Selama Resesi Hebat: Analisis Antar Kota, memberikan penjelasan bahwa Penggangguran adalah salah satu indikator ekonomi terpenting yang sering dipantau baik oleh masyarakat maupun pembuat kebijakan.

Visi Indonesia 2030 menyatakan Indonesia akan menjadi kekuatan kelima di dunia pada tahun 2030 bersama China, Amerika Serikat, India dan Uni Eropa. Jumlah penduduk Indonesia sebesar 285 Juta jiwa, Produk Domestik Bruto (PDB) Indonesia mencapai US \$ 5,1 Trilyun dan pendapatan perkapita Indonesia US \$ 180 ribu Trilyun. Untuk mencapai asumsi tersebut, Indonesia harus mencapai pertumbuhan ekonomi riil rata - rata $7,62 \%$ per tahun, Laju Inflasi $4,95 \%$ per tahun dan pertumbuhan penduduk rata - rata $1,12 \%$ per tahun yang disampaikan secara resmi pada 22 maret 2007 oleh Ketua Yayasan Indonesia Forum, Chairul Tanjung dihadapan Presiden Susilo Bambang Yudhoyono. Menurut (Nishihara, et.al, 2018) Untuk mencapai visi masa depan yang diharapkan perlu memperhatikan dalam menciptakan pengetahuan baru, manajemen dan strategi.

Indonesia menghadapi beberapa tantangan kedepan yang harus segera dipersiapkan lebih dini lagi. Pasar Bebas ASEAN 2015 dan Bonus Demografi 2025 akan menjadi tantangan sekaligus peluang bagi Indonesia untuk mempersiapkan diri menuju Visi Indonesia 2030. persiapan dini tersebut, terutama dalam hal mempersiapkan Sumber Daya Manusia (SDM) yang siap berdaya saing. Dalam penelitian mengenai pendidikan karakter dan nilai-nilai multikultur memberikan hasil dan kesimpulan bahwa Bonus Demografi ini akan menjadi faktor penting bagi pembangunan nasional jika dikelola dengan baik. Namun, jika dikelola dengan tidak tepat maka hal itu akan berdampak buruk bagi Pemerintah (Malihah, 2015)

Salah satu isu yang paling sering menjadi bahan perbincangan oleh berbagai kalangan di Indonesia dalam menghadapi MEA ini antara lain pada sektor tenaga kerja. Dengan ASEAN Community yang sudah diberlakukan sejak tahun 2015 maka human movement sudah semakin mudah dan bebas, tenaga kerja dari negaranegara ASEAN sudah dengan mudah masuk ke Indonesia sehingga persaingan di bursa tenaga kerja akan semakin ketat. ASEAN Economic Community bisa digambarkan sebagai salah satu kawasan ekonomi tanpa frontier atau batas antar 
negara. Sebab itu setiap penduduk maupun sumber daya dari setiap negara anggota bisa bergerak bebas seperti di dalam negeri sendiri. Indonesia juga akan menjadi pasar bagi produk dan tenaga kerja dari negara-negara ASEAN. Arus produk dan jasa/ tenaga kerja dari negara ASEAN tidak dapat dibendung lagi. Sebaliknya, Indonesia juga akan memiliki pasar yang lebih luas (baik bagi produk maupun tenaga kerjanya), dan hal ini merupakan peluang yang harus dapat dimanfaatkan dengan baik. Untuk dapat memanfaatkan peluang tersebut dan agar dapat memenangkan persaingan, maka setiap orang perlu meningkatkan knowledge, skill dan attitude-nya.

Menurut survei angkatan kerja nasional yang dilakukan oleh Badan Pusat Statistik yang dapat dilihat pada gambar 1, hingga Agustus 2019 terdapat 133,56 juta orang angkatan kerja dari 197,91 juta orang penduduk yang berumur 15 tahun keatas (Penduduk Usia Kerja). Dari jumlah angkatan kerja tersebut sebanyak 126,51 juta orang bekerja. Masalah yang dihadapi pemerintah adalah jumlah pengangguran bersifat terbuka yang mencapai 7,05 juta jiwa. berdasarkan tingkat pendidikan pada Agustus 2019 mayoritas penggangguran adalah lulusan Sekolah Menengah Kejuruan (SMK) dengan persentase $10.42 \%$, peringkat kedua adalah Sekolah Menengah Atas (SMA) menempati peringkat kedua dengan persentase 7,92 \%, diikuti Diploma I/II/III 5,99 \%, Universitas 5,67 \%, Sekolah Menengah Pertama 4,75 \%, dan Sekolah Dasar 2,41 \%.

Indonesia berada pada peringkat 150 dari 196 negara dan kedua dari bawah di ASEAN Untuk indikator knowledge-intensive employment yang dapat dilihat pada gambar 2. Indonesia kekurangan tenaga kerja terampil yang memiliki pengetahuan yang tinggi. Dari data-data yang terlihat pada gambar 2 dalam posisi sumber daya manusia Indonesia masih tertinggal dari negara-negara ASEAN lainnya.

Pendidikan dan Pelatihan merupakan bagian yang tak terpisahkan dari kebijakan pengembangan Sumber Daya Manusia (SDM) dalam rangka meningkatkan pengetahuan. Menurut (Eichhorst et al., 2015) dalam pernelitiannya mengenai vocational education, desimpulkan bahwa Lembaga Pendidikan dan pelatihan kejuruan (Diklat) sering dianggap sebagai solusi untuk meningkatkan peluang kaum muda yang tidak memiliki sumber daya, keterampilan, atau motivasi untuk melanjutkan pendidikan tinggi. upaya peningkatan kompetensi Sumber Daya Manusia (SDM) menjadi hal yang sangat penting untuk dapat memenangkan persaingan tenaga kerja di era globalisasi. Penyelenggaraan pendidikan dan pelatihan (Diklat) berbasis kompetensi yang sesuai dengan kebutuhan dunia usaha terutama sektor industri menjadi salah satu upaya yang dapat dilakukan dalam peningkatan kualitas Sumber Daya Manusia (SDM).

Institusi Penidikan dan Pelatihan mempunyai peranan penting sebagai sumber knowledge creation dalam membentuk knowledge, skill dan attitude para calon peserta pelatihan yang akan dilatih nantinya agar dapat menjadi pekerja yang kompeten dan profesional dalam mengatasi permasalahan kebutuhan tenaga kerja. 
Ide-ide baru yang berasal dari pengolahan ilmu pengetahuan dari anggota organisasi khususnya organisasi sektor publik diharapkan akan menghasilkan inovasi dalam memberikan pelayanan yang terbaik kepada masyarakat sekaligus akan berdampak pada peningkatan kinerja Unit Kerja. Menurut penelitian (Pribadi, 2010) untuk menghasilkan inovasi, fokus utamanya adalah pada creating knowledge, terutama pada tacit knowledge yang dapat membentuk kemampuan Perusahaan dan dengan kemampuan perusahaan tersebut dapat menciptakan ideide inovasi praktis.

Wahyudi \& Andreo, (2011) mengemukakan bahwa dalam mentransformasi pengetahuan, organisasi secara berkelanjutan mencari pengetahuan baru melalui pengembangan dan pembagian hasil suatu ide atau pemikiran kreatif, dan pengetahuan eksplisit sehingga menghasilkan produk dan inovasi baru. Organisasi bisa disebut memiliki knowing (pengetahuan) apabila mampu beradaptasi terhadap lingkungan di waktu yang tepat dan cara yang efektif (sensemaking), terus menerus belajar dengan menguji dan melupakan mental model yang sudah tidak valid lagi, dan memobilisasi pengetahuan serta keahliannya (knowledge creating), dan mengambil keputusan berdasarkan pengetahuan (decision making). knowledge creation dapat didefinisikan juga sebagai suatu proses organisasi dalam menemukan dan mendefinisikan suatu masalah untuk dapat menemukan ide atau pengetahuan baru dalam memecahkan permasalahan tersebut (Nonaka, 1995). Dengan demikian konsep kreativitas dan inovasi menjadi bagian yang terikat ketika organisasi menghasilkan pengetahuan baru. Pengertian tersebut secara tidak langsung menyampaikan bahwa indikator dalam menghasilkan pengetahuan dalam sebuah organisasi adalah inovasi. Inovasi tersebut bisa dalam bentuk produk, pelayanan maupun sistem yang baru.

Hidayat et al., (2018) dalam penelitiannya mengenai peran perilaku inovativ dalam variabel intervening antara knowledge creation dan keunggulan bersaing mengemukakan bahwa penerapan knowledge creation memiliki pengaruh yang positif dan signifikan terhadap perilaku inovatif. Proses penciptaan pengetahuan diperoleh dengan empat mode melalui konversi pengetahuan tacit. Keempat mode tersebut adalah Sosialisasi, eksternalisasi, kombinasi dan internalisasi (SECI) (Nonaka, 1995). Proses Sosialisasi adalah suatu proses perpindahan pengetahuan tacit ke pengetahuan tacit dengan cara berbagi pengalaman seperti mental model dan keahlian teknis. Proses Eksternalisasi adalah suatu proses perpindahan pengetahuan tacit ke pengetahuan eksplisit melalui suatu konsep. Proses kombinasi adalah suatu proses perpindahan transfer pengetahuan eksplisit yang sudah ada menjadi pengetahuan eksplisit yang baru. Proses Internalisasi adalah suatu proses perpindahan pengetahuan eksplisit ke tacit melalui learning by doing.

Berdasarkan latar belakang dan penelitian terdahulu di atas, menunjukan bahwa knowledge creation bagi Insttitusi pendidikan dan pelatihan sangat penting agar dapat menghasilkan inovasi maupun ide-ide baru dalam upaya meningkatkan kinerja organisasi baik melalui sistem pelayanan penyelenggaraan pendidikan dan 
pelatihan yang baru maupun mengadopsi dari sistem pelayanan penyelenggaraan pendidikan dan pelatihan yang sudah ada. Institusi Pendidikan dan Pelatihan perlu menjadi organisasi yang terus belajar dimana individu-individu di dalamnya harus terus mengembangkan pengetahuan yang dimilikinya sehingga dapat menghasilkan diklat yang berkualitas dan menciptakan tenaga kerja yang dibutuhkan oleh dunia usaha. Penelitian ini lebih jauh akan membahas mengenai bagaimana proses knowledge creation dapat diwujudkan dalam institusi Pendidikan dan pelatihan. Penelitian ini bertujuan untuk menganalisis proses knowledge creation dan kendala yang dihadapi di Pusat Pendidikan dan Pelatihan pegawai Kementerian Ketenagakerjaan ditinjau dari pendekatan SECI Nonaka

\section{METODE PENELITIAN}

Penelitian ini merupakan penelitian kualitatif, penelitian kualitatif adalah Penelitian yang cenderung menggunakan analisin dan menggunakan metode deskriptif, memberikan gambaran umum tentang deskripsi penelitian. Penelitian ini menggunakan metode studi literatur dengan mengumpulkan data, kajian, laporan, publikasi, buku maupun berita tentang analisis knowledge creation. Dimaksud dengan studi literatur adalah ringkasan tertulis mengenai artikel dari jurnal, buku dan dokumen lain yang mendeskripsikan teori serta informasi, baik masa lalu maupun saat ini, mengorganisasikan pustaka dalam topik dan dokumen yang dibutuhkan untuk suatu penelitian. Data dalam penelitian ini diperoleh dari studi literature penelitian lain berupa jurnal, buku dan dokumen lain yang memuat penelitian terkait dengan topik knowledge creation. Oleh karena itu, dengan melakukan studi literatur, penulis berharap mendapatkan teori serta kerangka pemikiran yang relevan dengan permasalahan analisis knowledge creation dalam institusi Pendidikan dan pelatihan.

\section{HASIL PENELITIAN}

\section{Konsep Knowledge creation}

Pengetahuan merupakan asset dengan nilai strategis yang sangat besar. (Sallán et al., 2012) mengemukakan bahwa di dalam kelompok bidang pengetahuan dan pembelajaran saat ini, pengetahuan menjadi aset dengan nilai strategis yang sangat besar, dan untuk alasan itu, organisasi menemukan diri mereka larut dalam pencarian strategi baru yang akan membebaskan anggota mereka untuk membuat dan berbagi pengalaman, kesan, dan pengetahuan, Menurut (Nishihara, Ayano Hirose., Matsunaga, Masaei., Nonaka, Ikujiro., Yokomichi, 2018) Untuk mencapai visi masa depan yang diharapkan kita perlu memperhatikan dalam menciptakan pengetahuan baru, manajemen dan strategi. Berdasarkan beberapa pendapat tersebut, dapat disimpulkan bahwa pengetahuan merupakan aset utama dan kunci kekuatan organisasi untuk mengidentifikasi dan memecahkan masalah sebagai sumber kekuatan dan daya saing agar organisasi dapat bertahan dan berkompetisi dengan negara-negara lain di seluruh dunia. 
Merujuk pada beberapa pendapat pakar tersebut, dapat diambil kesimpulan bahwa knowledge bukan hanya kumpulan dari data dan informasi yang kontekstual dan memiliki makna yang diperoleh melalui pengalaman, nilai dan wawasan, namun lebih dari itu knowledge merupakan sebuah proses interaksi sosial yang dinamis antar individu dalam organisasi dengan bekal pengalaman dan wawasan yang menuntun individu tersebut dalam bertindak dan melakukan pekerjaannya untuk memecahkan masalah.

Pendekatan modern memandang organisasi sebagai sebuah sistem yang terbuka yang tidak dapat dipisahkan dari lingkungan. (Lubis, 2009) mengungkapkan bahwa organisasi yang dapat menyesuaikan diri secara tepat dengan tuntutan lingkungan akan dapat mencapai keberhasilannya. Pandangan tersebut sekaligus melihat bahwa organisasi sebagai sebuah sistem dinamis yang perlu melakukan perubahan serta inovasi secara terus menerus agar dapat bertahan menghadapi lingkungan yang terus berubah.

Mitchell \& Boyle, (2010) mendefinisikan knowledge creation sebagai turunan, pengembangan dan eksploitasi dari ide baru. Knowledge creation merujuk pada organisasi yang memfasilitasi anggotanya untuk berinovasi dalam bentuk ide, pengetahuan, produk maupun pelayanan baru sehingga menjadikan organisasi memiliki daya saing. Komponen dari knowledge creation menurut Mitchell \& Boyle, (2010) terdiri dari proses, output dan outcome. Sebagai sebuah proses, knowledge creation merujuk pada inisiatif dan aktivitas yang dilakukan untuk menghasilkan ide baru untuk mengatasi masalah, kemudian bila dilihat sebagai keluaran maka penciptaan pengetahuan merujuk pada pengembangan gagasan baru dari elaborasi pengetahuan yang ada baik dalam bentuk produk maupun pelayanan. Bila dilihat dari sisi dampak, penciptaan pengetahuan merujuk pada produk maupun pelayanan baru yang diadopsi dan disebarkan sehingga berdampak pada sistem baru organisasi.

Bratianu, (2010) menjelaskan bahwa dalam organisasi, proses knowledge creation merupakan proses interaksi individu yang dinamis yang menghilangkan batasan antar mereka sehingga dapat menghasilkan sebuah perubahan dalam organisasi. Cong et al., (2007) bahwa penciptaan pengetahuan merupakan sebuah proses dimana organisasi menyerap pengetahuan dari para pegawai untuk menciptakan pengetahuan baru yang dapat diaplikasikan dalam pekerjaan seharihari dan merupakan proses siklis yang berlangsung terus menerus.

Penciptaan pengetahuan tidak terlepas dari proses pembelajaran individu dalam organisasi. Kim \& Sloan, (1993) mengemukakan pembelajaran individu yang meliputi proses Observe-Assess-Design-Implement atau yang dikenal dengan istilah OADI. observasi mengenai apa yang terjadi berdasarkan pengalaman, kemudian proses asses yang merupakan refleksi dari observasi pengalaman, kemudian proses disain dari refleksi tersebut dalam bentuk konsep dan konsep tersebut diuji coba dalam bentuk implementasi sehingga menghasilkan pengalaman konkrit yang baru. Konsep pembelajaran individu tersebut kemudian digunakan 
untuk menghubungkan pembelajaran individu dengan organisasi dalam rangka meningkatkan pembelajaran organisasi.

Nonaka, et.al, (2001) menjelaskan bahwa organisasi mengkreasi pengetahuan melalui interaksi antara pengetahuan tacit dan pengetahuan ekspilisit. Terkait dengan kedua pengetahuan tersebut, Nonaka memandang knowledge creation dalam dua dimensi yaitu dimensi ontologi dan dimensi epistimologi. Dimensi ontologi menjelaskan mengenai keberadaan suatu pengetahuan. Dimensi ontologi menurut Nonaka menjelaskan bahwa pengetahuan dapat dibangun melalui berbagi ide dan cerita dalam kelompok/grup. Melalui berbagi ide tersebut dapat membantu memecahkan masalah dan memberikan kontribusi untuk belajar melalui tindakan yang merupakan salah satu bagian penting dalam knowledge creation

Dimensi kedua yaitu dimensi epistimologi yang memandang pengetahuan dari sisi keilmuan dan filosofi atau terkait dengan teori pengetahuan. Menurut dimensi epistimologi, pengetahuan dapat menjadi objektif maupun subjektif. Pengetahuan menjadi suatu konsep yang objektif ketika pengetahuan dapat diperoleh dan dibagikan yang dikenal sebagai pengetahuan eksplisit.

Model knowledge creation dikemukakan oleh berbagai ahli dalam berbagai model. Konsep tersebut diantaranya yaitu:

1. Model Soo et al., (2002) dengan pendekatan pentingnya memahami organisasi dari sisi input sampai dengan output. Model yang dikemukakan oleh pakar tersebut menjelaskan bahwa proses penciptaan pengetahuan berasal dari akuisisi pengetahuan (knowledge acquisition) yang diperoleh dari jaringan yang dibangun organisasi dengan lingkungan, selanjutnya organisasi perlu mengenali informasi yang berasal dari lingkungan yang berpengaruh terhadap organisasi (absorptive capacity) dan menggunakannya untuk memecahkan masalah (problem solving) pada organisasi sehingga organisasi dapat menciptakan pengetahuan baru dan inovasi untuk meningkatkan kinerja keuangan organisasi. Model ini lebih menekankan pada pengetahuan diperoleh dari luar organisasi, namun mengabaikan sisi pembelajaran di dalam organisasi. Menurut model ini, inovasi hanya tercipta apabila organisasi menyerap banyak pengetahuan dari lingkungannya. Metode memiliki kekurangan sebab penelitian akan berfokus dalam penciptaan pengetahuan yang berasal dari faktor-faktor dari luar organisasi.

2. Model Boisot dalam Dalkir, (2005) menekankan pada teori informasi yang divisualisasikan dalam tiga dimensi yaitu (1) kodefikasi yang menjelaskan cara mengkategorikan dan mengklasifikasikan pengetahuan eksplisit (2) abstrak yang menjelaskan penciptaan pengetahuan melalui analisis dan pemahaman terhadap informasi yang telah dikodefikasi dan (3) difusi yang menjelaskan akses informasi dan penyebarannya dalam organisasi. Ketiga dimensi tersebut yang akan mempengaruhi pembelajaran. Pendekatan ini membutuhkan berbagi konteks melalui interaksi antar individu yang dianalogikan seperti internalisasi dalam konversi pengetahuan SECI dari 
Nonaka dan Takeuchi. Metode ini memiliki kekurangan yaitu hanya berfokus pada dimensi internalisasi saja.

3. Nonaka dan Takeuchi yang menggunakan model SECI (Socialization, Externalization, Combination dan Internalization) dalam menciptakan pengetahuan baru di organisasi melalui konversi pengetahuan tacit dan explicit. Konsep ini menekankan pada pengetahuan apa yang dibutuhkan organisasi dalam menghasilkan pengetahuan baru serta bagaimana proses konversi pengetahuan yang terjadi antara individu, kelompok organisasi dan antar organisasi untuk memperoleh dan menciptakan pengetahuan baru.

Pada dasarnya konsep pertama dan kedua merupakan pengembangan dari konsep SECI yang dikemukakan oleh Nonaka. konversi pengetahuan dalam bentuk sosialisasi, eksternalisasi, kombinasi dan internalisasi yang merupakan sebuah siklus dan berlangsung secara terus menerus yang dapat dilihat pada gambar 3 . Pada dasarnya konsep pertama dan kedua merupakan pengembangan dari konsep SECI yang dikemukakan oleh Nonaka.

Model SECI dari Nonaka dan Takeuchi memiliki beberapa kelebihan pertama, proses penciptaan pengetahuan dalam konsep tersebut digambarkan secara lebih sederhana namun secara lengkap menjelaskan proses penciptaan pengetahuan dalam organisasi. Kedua, konsep tersebut mencakup tidak hanya pengetahuan apa yang diperlukan dalam organisasi dan bagaimana proses organisasi menciptakan pengetahuan baru, namun juga menjelaskan pembelajaran secara menyeluruh mulai dari level individu, kelompok, organisasi bahkan inter organsisasi. Ketiga, konsep tersebut tidak hanya sebatas pada penciptaan pengetahuan namun mencakup transfer pengetahuan yang ada dimana kedua hal tersebut menjadi sesuatu yang penting dalam mengembangkan pengetahuan organisasi untuk memperkuat posisi organisasi dan menjadikannya berdaya saing.

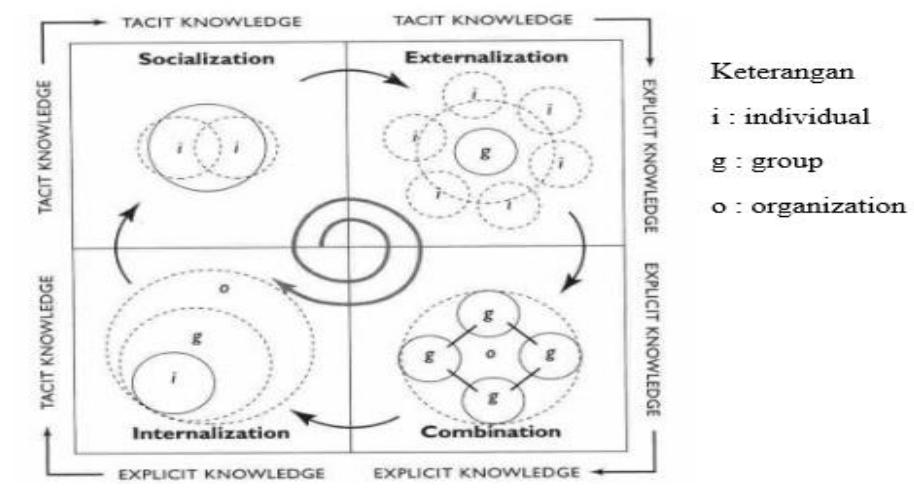

Sumber : (I. Nonaka \& Konno, 1998)

Gambar 1. Model SECI Knowledge Creation Nonaka dan Takeuchi

Sosialisasi menjadi tahap awal dari proses SECI. Sosialisasi merupakan proses konversi pengetahuan dari tacit ke tacit. bahwa individu dapat memperoleh pengetahuan secara langsung dengan cara mengalami sendiri dari individu lainnya. 
Hal ini dapat dilakukan dengan atau tanpa melalui percakapan. Pendampingan pekerjaan dengan atasan atau expert dapat dilakukan secara langsung tanpa melalui percakapan atau dialog seperti observasi, imitasi dan praktek. Dunia bisnis menggunakan cara on the job training agar individu dapat melakukan pengamatan secara langsung atau bahkan terlibat didalamnya sehingga mendapatkan pengetahuan dan keahlian sebab kata kunci untuk memperoleh pengetahuan tacit adalah pengalaman.

Eksternalisasi merupakan proses artikulasi pengetahuan tacit menjadi eksplisit dalam sebuah konsep. Proses ini melibatkan perpindahan pengetahuan dari level individu ke level kelompok/ grup. Eksternalisasi dipandang sebagai sebuah proses klasik dari knowledge creation dimana pengetahuan tacit dikonversi menjadi eksplisit melalui metafora, analogi, konsep, hipotesis dan model.

Kombinasi merupakan proses mengkreasi pengetahuan eksplisit yang baru dari pengetahuan eksplisit yang telah ada. Proses ini melibatkan perpindahan pengetahuan dari level kelompok ke level organisasi. Contoh lainnya dari kombinasi adalah forum akademik, dan proses penelitian. Output dari kombinasi akan menghasilkan pengetahuan sistemik (systemic knowledge). Dapat disimpulkan bahwa proses kombinasi adalah merupakan konversi pengetahuan dari pengetahuan eksplisit yang sudah ada untuk dapat menghasilkan pengetahuan eksplisit yang baru melalui rekonfigurasi dan kombinasi pengetahuan yang sudah ada.

Internalisasi merupakan proses konversi pengetahuan dari pengetahuan eksplisit menjadi pengetahuan tacit. Proses ini terkait dengan "learning by doing". Proses ini terjadi pada level individu, kelompok dan organisasi. Internalisasi menghasilkan pengetahuan operasional (operational knowledge) tentang manajemen proyek, proses produksi, kegunaan produk baru, dan implementasi kebijakan. Dapat diambil kesimpulan bahwa internalisasi merupakan proses konversi pengetahuan dari pengetahuan eksplisit menjadi pengetahuan tacit melalui "learning by doing".

Tabel 1. Proses SECI dan Contoh

\begin{tabular}{cllll}
\hline & & & & \\
& & & & \\
& & & & \\
& & & & \\
& & & & \\
\hline Tipe konversi & Tacit $\mathrm{ke}$ & Tacit $\mathrm{ke}$ & Eksplisit & Eksplisit ke \\
pengetahuan & tacit & eksplisit & ke eksplisit & tacit \\
\hline Level & Individ & Individu & Kelompok & Organisasi \\
perubahan & $\mathrm{u}$ & ke & ke & ke individu \\
pengetahuan & ke & kelompok & organisasi & \\
& individu & & & \\
\hline Contoh & On the & Metaphora & Proses & Implementa \\
& job &, & penelitian & si \\
& training & konsep & & kebijakan \\
\hline
\end{tabular}

Sumber : (Hislop, 2013) diolah oleh Peneliti 
Model SECI yang dapatdilihat pada Tabel 1 mendeskripsikan proses dinamis pergerakan pengetahuan berbasis dimensi epistimologi dimana terjadi konversi pengetahuan eksplisit dan tacit serta dari dimensi ontologi dalam proses spiral yang bergerak dari level individu menuju level kelompok, organisasi dan inter organisasi. Interaksi kedua pengetahuan tersebut akan memperbesar dimensi keberadaan pengetahuan dari level individu sampai dengan antar organisasi serta area perpindahan pengetahuan tacit dan eksplisit yang digambarkan dalam bentuk spiral. Kreasi pengetahuan dalam proses SECI dapat menjadi pemicu dalam membentuk spiral baru knowledge creation.

\section{PEMBAHASAN}

\section{Hubungan Pendidikan dan Pelatihan (Diklat) dengan Pembelajaran dan Knowledge Creation}

Menurut Weinhardt \& Sitzmann, (2019) Pelatihan dan pendidikan memberikan kesempatan bagi individu untuk meningkatkan keterampilan, hubungan, sikap, pola pikir, kinerja perusahaan, dan banyak lagi dan Pelatihan juga merupakan aset yang dapat digunakan organisasi untuk meningkatkan keunggulan kompetitif mereka. Mondy, (2012) berpendapat bahwa pelatihan dirancang untuk meningkatkan pengetahuan dan keterampilan yang dibutuhkan untuk pekerjaan saat ini. Pelatihan menurut Dessler, (2012) adalah upaya yang dilakukan oleh organisasi untuk meningkatkan kinerja dalam memberikan keahlian/keterampilan yang dibutuhkan oleh pegawai baru maupun yang telah bekerja

Penggunaan istilah "Diklat" sering digunakan oleh institusi untuk menyebut istilah pendidikan dan pelatihan. Pendidikan lebih menekankan pada pemberian pengetahuan (knowledge) yang secara analogi berada didalam pikiran manusia baik yang baru maupun yang sudah ada dalam usaha memperkaya pengetahuan dan wawasan. sedangkan pelatihan dibuthkan untuk memberikan keterampilan (skill) baru, belum ada atau meningkatkan keterampilan yang telah dikuasai seseorang. Berdasarkan pendapat tersebut, dapat diambil kesimpulan bahwa pendidikan dan Pelatihan (Diklat), pada dasarnya adalah kegiatan untuk menambah pengetahuan, keterampilan dan sikap bagi para pegawai baru, pegawai yang sudah bekerja

Salah satu penelitian yang dilakukan terkait Knowledge creation dilakukan oleh Mundiarsih, (2017) yang berjudul "Analisis Knowledge creation di Pusat Pendidikan Dan Pelatihan Pegawai Kementerian Ketenagakerjaan". Penelitian dilakukan dengan metode Kualitatif. Tujuan penelitian ini adalah untuk menganalisis proses knowledge creation dan kendala yang dihadapi di Pusat Pendidikan dan Pelatihan pegawai Kementerian Ketenagakerjaan ditinjau dari pendekatan SECI Nonaka. Hasil penelitian menunjukkan bahwa proses knowledge creation ditinjau dari pendekatan SECI belum sepenuhnya terjadi karena lebih didominasi oleh pengetahuan explicit dan lebih dominan pada tahap kombinasi.

Menurut Mello, (2015), proses dalam pelaksanaan pendidikan dan pelatihan adalah perencanaan yang berisi dengan kegiatan analisis kebutuhan dan 
menentukan desain, strategi, transfer, dan proses pembelajaran dalam pelatihan. Penyampaian materi pembelajaran dalam pendidikan dan pelatihan disesuaikan dengan pengetahuan yang dibutuhkan dalam melakukan suatu pekerjaan. Serta tahap evaluasi untuk dapat mengevaluasi efektifitas pelatihan, pengajar dan fasilitas yang diberikan. Evaluasi dalam pembelajaran dilakukan untuk mengetahui seberapa besar pengetahuan baru yang diterima peserta diklat saat mengikuti pelatihan. Evaluasi dalam perilaku dilakukan setelah pelatihan dilaksanakan, serta dampak dari pelatihan yang sudah dilaksanakan. Menurut Noe, (2010), proses dalam pelatihan dan pengembangan terdiri dari kegiatan analisis kebutuhan untutk menentukan calon peserta yang perlu untuk mengikuti pelatihan, materi dan keahlian apa saja yang dibutuhkan, menentukan pengajar yang akan memberikan materi pelatihan, pengelolaan mekanisme pembelajaran dalam kelas, dan rencana pembelajaran. Pengetahuan tentang karakteristik peserta juga dibutuhkan dalam rangka menciptakan suasana pembelajaran yang baik.

Pendapat tersebut diatas menjelaskan bahwa dalam menyelenggarakan pendidikan dan pelatihan, dibutuhkan beberapa tahap, tahap pertama adalah perencanaan dalam menganalisis berapa kebutuhan peserta yang diklat yang perlu untuk mengikuti pelatihan. Kedua, materi dan keahlian apa yang dibutuhkan oleh peserta diklat. Ketiga, tahap pelaksanaan untuk menentukan siapa dan berapa banyak pengajar yang dibutuhkan. Keempat, menentukan mekanisme pengelolaan kelas, rencana pembelajaran, transfer pembelajaran dan evaluasi pelatihan.

Pendidikan dan pelatihan dalam keterkaitannya dengan pembelajaran adalah melalui pelatihan, peserta diklat akan diberikan informasi oleh organisasi, dan melalui mekanisme pembelajaran, pegawai didorong oleh organisasi untuk bertanya, berfikir kritis dan menemukan jawaban atas permasalahan dengan sendirinya (Walter Kiechel dalam (Marquardt, 2002). Berdasarkan pernyataan tersebut dapat disimpulkan bahwa untuk menciptakan pembelajaran organisasi, belajar saat pelatihan saja belum cukup. Pembelajaran harus terus berkesinambungan secara terus menerus sehingga para peserta diklat tidak hanya mendapatkan informasi atau pengetahuan baru yang diberikan dalam pelatihan namun juga dapat menemukan solusi baru terhadap suatu permasalahan dengan cara ataupun metode yang lain. Model yang digunakan dalam menciptakan pengetahuan baru juga harus dapat disesuaikan pada kebutuhan pendidikan dan pelatihan yang akan dilaksanakan.

\section{SIMPULAN}

Berdasarkan hasil studi literatur terhadap analisis knowledge creation dalam institusi pendidikan dan pelatihan, maka penulis menyajikan tiga model pendekatan yang dapat digunakan sebagai rujukan dalam menganalisa proses knowledge creation. Model pertama yaitu model knowledge creation Soo. Model ini lebih menekankan pada pengetahuan diperoleh dari luar organisasi. Dimensi yang disampaikan adalah akuisisi pengetahuan, absorptive capacity, dan 
pemecahan masalah.Model kedua adalah Model Boisot yang menekankan pada teori informasi yang divisualisasikan dalam tiga dimensi yaitu kodefikasi, abstrak dan difusi. Model ketiga adalah model SECI Nonaka dan Takeuchi. Model ini menekankan pada penciptaan pengetahuan baru di organisasi melalui konversi pengetahuan tacit dan explicit dengan dimensi Socialization, Externalization, Combination dan Internalization.

\section{DAFTAR PUSTAKA}

Bratianu, C. \& O. I. (2010). Organizational Knowledge Creation, Management marketing challanges for knowlege society. 5(3), 41-62.

Choo, C. W. (1996). The knowing organization: How organizations use information to construct meaning, create knowledge and make decisions. International Journal of Information Management. https://doi.org/10.1016/0268-4012(96)00020-5

Cong, X., Li-Hua, R., \& Stonehouse, G. (2007). Knowledge management in the Chinese public sector: empirical investigation. Journal of Technology Management in China, 2(3), 250-263. https://doi.org/10.1108/17468770710825188

Creswell, J. W. (2009). Research Design: Qualitative, Quantitative and Mixed Approaches (3rd Edition). In Research Design: Qualitative, Quantitative, and Mixed Methods Approaches. https://doi.org/10.2307/1523157

Dalkir, K. (2005). Knowledge management in theory and practice. Elsevier Inc.

Dessler, G. (2012). Human Resource Management. John Willey and Sons.

Eichhorst, W., Rodríguez-Planas, N., Schmidl, R., \& Zimermann, K. F. (2015). A road map to vocational education and training in industrialized countries. Industrial and Labor Relations Review, 68(2), 314-337. https://doi.org/10.1177/0019793914564963

Hidayat, A. S., Setiawan, Y., Alwi, M., \& Nurdiana, E. (2018). Peran Perilaku Inovatif Sebagai Variabel Intervening antara Knowledge Creation dan Keunggulan Bersaing. Jurnal Ecodemica, 2(2).

Hislop. (2013). Knowledge management in organizations a critical introduction. Oxford University Press.

Kim, D. H., \& Kim Sloan, D. H. (1993). The Link between Individual and Organizational Learning INDIVDUAL LEARNING. Management Review, $35,37-50$.

Lubis, H. \& M. H. (2009). Pengantar Teori Organisasi: Suatu Pendekatan Makro.

Malihah, E. (2015). An ideal Indonesian in an increasingly competitive world: Personal character and values required to realise a projected 2045 'Golden Indonesia.' Citizenship, Social and Economics Education, 14(2), 148-156. https://doi.org/10.1177/2047173415597143

Marquardt, M. . (2002). Building The Learning Organization. Davie Black Publishing, Inc.

Mello, J. A. (2015). Strategic Human Resource Management. Cengage Learning.

Mitchell, R., \& Boyle, B. (2010). Knowledge creation measurement methods. Journal of Knowledge Management, 14(1), 67-82. 
https://doi.org/10.1108/13673271011015570

Mondy, R. W. (2012). Manajemen Sumber Daya Manusia Edisi 10 (1st ed.). Erlangga.

Mundiarsih, A. P. (2017). Analisis Knowledge Creation Di Pusat Pendidikan Dan Pelatihan Pegawai Kementerian Ketenagakerjaan. Universitas Indonesia.

Nishihara, Ayano Hirose., Matsunaga, Masaei., Nonaka, Ikujiro., Yokomichi, K. (2018). Knowledge Creation In Public Administrations: Innovative Government in Southeast Asia and Japan. Palgrave Macmillan.

Noe, R. A. (2010). Employee training and development. Mc Graw Hill.

Nonaka, Ikujiro and Teece, D. (2001). Managing industrial knowledge : creation, transfer and utilization. Sage Publications.

Nonaka, I. and H. T. (1995). The Knowledge Creating Company. Oxford University Press.

Nonaka, I., \& Konno, N. (1998). The concept of "Ba": Building a foundation for knowledge creation. California Management Review, 40(3), 44-45. https://doi.org/10.2307/41165942

Pribadi, H. (2010). Ba, Japanese-Style Knowledge Creation Concept:A Building Brick of Innovation Process inside Organization. Jurnal Teknik Industri, 12(1), 1-8.

Sallán, J. G., de Álava, M. F., Barrera-Corominas, A., \& Rodríguez-Gómez, D. (2012). Review of Knowledge Creation and Management Processes Through Communities of Practice in Public Administration. Procedia Social and Behavioral Sciences, 46, 2198-2204. https://doi.org/10.1016/j.sbspro.2012.05.454

Soo, C., Devinney, T., Midgley, D., \& Deering, A. (2002). Knowledge management: Philosophy, processes, and pitfalls. California Management Review, 44(4). https://doi.org/10.2307/41166146

Sugiyono. (2016). Memahami Penelitian Kualitatif. Bandung: Alfabeta.

Van Gent, T., Khan, F. C., \& Cloutier, N. (2019). Industrial Effects on Male and Female Unemployment Over the Great Recession: An Interurban Analysis. The American Economist, 64(1), 19-30. https://doi.org/10.1177/0569434517745558

Wahyudi Andreo. (2011). Dinamika knowing organization. Yayasan Rabi.

Weinhardt, J. M., \& Sitzmann, T. (2019). Revolutionizing training and education? Three questions regarding massive open online courses (MOOCs). Human Resource Management Review, 218-225. https://doi.org/10.1016/j.hrmr.2018.06.004 